\title{
Toll-like receptor 7 function is reduced in adolescents with asthma
}

\author{
M. Roponen*,\#,+, S.T. Yerkovich ${ }^{\star, \uparrow,+}$, E. Hollams*, P.D. Sly*, \\ P.G. Holt* and J.W. Upham*^ף
}

ABSTRACT: Anti-viral innate immune responses may be impaired in asthma, although the mechanisms are not well understood. Toll-like receptors (TLRs) 7 and 3 are particularly relevant for initiating responses to common respiratory viruses, as they recognise single-stranded viral RNA and double-stranded viral RNA, respectively. The aim of the present study was to investigate TLR7 and TLR3 function in 14-yr-old adolescents with asthma.

Blood mononuclear cells obtained from 17 atopic asthmatics, 29 atopic, non-asthmatics and 21 healthy, non-atopic individuals, were stimulated with the TLR7 agonist imiquimod and the TLR3 agonist poly I:C. Expression of anti-viral molecules was measured by real-time PCR. Concentrations of interferon- $\gamma$-inducible cytokine protein (IP)-10 and interleukin (IL)-6 were measured by ELISA.

TLR7-induced myxovirus resistance protein $A$ and $2^{\prime} 5^{\prime}$ oligoadenylate synthetase mRNA expression and protein levels of IP-10 were significantly lower in asthma subjects compared with healthy subjects $(p=0.041, p=0.003$ and $p=0.001$ respectively). There was a significant negative correlation between total serum immunoglobulin E and IP-10 following TLR7 stimulation. However, TLR3-induced responses did not vary with asthma or atopy. IL-10 mRNA and IL-6 protein synthesis were similar in asthmatic and control subjects. In conclusion, TLR7 function is reduced in adolescents with asthma and this may contribute to susceptibility to respiratory viral infections.

KEYWORDS: Asthma, innate immunity, Toll-like receptor, virus

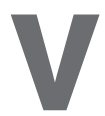

iral respiratory infections, especially with rhinovirus (RV), are a major cause of asthma exacerbations in children and adults [1-3]. Adults with asthma do not necessarily have more frequent $\mathrm{RV}$ infections than healthy individuals, but when RV infections occur they induce more frequent and longer lasting lower respiratory tract symptoms [4].

The mechanisms by which viral infections aggravate airway inflammation and hyperresponsiveness in asthma are complex and not fully understood, although defects in anti-viral immune responses are increasingly recognised. Viraemia during acute RV infection is more commonly detected in children with acute asthma exacerbations than in non-asthmatic children with colds [5], suggesting that asthma is associated with a reduced ability to limit systemic spread of virus. Moreover, RV RNA can be detected in respiratory secretions in $>40 \%$ of asthmatic children several weeks after an acute exacerbation [6], implying a reduced capacity to either clear RV from the respiratory tract, or to prevent new infections during convalescence.

Recent studies have provided important insights into anti-viral innate immunity in asthma. When cultured bronchial epithelial cells are infected with RV, cells from asthmatic subjects produce less interferon (IFN)- $\beta$ and IFN- $\lambda$ relative to healthy donors $[7,8]$. Alveolar macrophages and circulating leukocytes from asthmatics also appear to have a deficient capacity to synthesise type I and type III IFN [7, 9, 10], suggesting that the impaired anti-viral response in asthma involves not just structural cells of the lung, but also migratory immune cells and their precursors within the circulation. However, the molecular mechanisms leading to altered anti-viral innate immunity in asthma are not clear.

The innate immune response to viral infections is a multistep process involving the initial detection of viral components, followed by the expression
AFFILIATIONS

*Telethon Institute for Child Health Research, Centre for Child Health Research, University of Western Australia, Perth, and

"The University of Queensland School of Medicine, Princess Alexandra Hospital, Brisbane, Australia.

${ }^{\text {\#}}$ National Institute for Health and Welfare, Kuopio, Finland.

${ }^{+}$Both authors contributed equally to this study.

CORRESPONDENCE

J.W. Upham

The University of Queensland School of Medicine

Princess Alexandra Hospital Ipswich Road

Buranda

Brisbane

Queensland 4102

Australia

E-mail: j.upham@uq.edu.au

Received:

Nov 122008

Accepted after revision:

July 162009

First published online:

July 302009 
of IFN regulatory factors (IRFs), subsequent IFN gene transcription, and finally the induction of a large family of "downstream" IFN-stimulated genes that induce an anti-viral state within cells, thereby limiting virus replication. Viruses are detected within cells by a family of cytoplasmic receptors and by viral-sensing Toll-like receptors (TLRs) that are located within endosomes [11, 12]. TLR7 and TLR3 are particularly relevant in relation to RNA viruses (e.g. RV, respiratory syncytial virus and influenza), as they recognise and respond to single-stranded viral RNA and double-stranded viral RNA (formed during viral replication), respectively.

The aims of this study were to examine TLR7 and TLR3 function in asthma. We hypothesised that asthma would be associated with deficiencies in TLR7 and/or TLR3 responsiveness. The primary end points of the study were expression of IRF7 (identified as a "master regulator" of anti-viral immunity [13]), two IFN-stimulated genes, myxovirus resistance protein A (MxA) and 2'5' oligoadenylate synthetase (OAS), and secretion of IFN- $\gamma$-inducible cytokine protein (IP)-10 (also known as CXCL10). Both MxA and OAS have direct anti-viral properties: MxA targets the nucleoproteins of a wide range of RNA viruses [14], whereas OAS enhances viral RNA degradation [15]. IP-10 acts as a chemoattractant for activated T-helper-1 cells and natural killer cells and has been closely linked to viral exacerbations of asthma [16]. In addition, we examined the pro-inflammatory cytokine interleukin (IL)-6, and the immune-regulatory cytokine IL-10.

We investigated these aims in a cohort of adolescents, using blood mononuclear cells stimulated with imiquimod, a synthetic TLR7 ligand, and polyinosinic acid:polycytidylic acid (poly I:C), a synthetic double-stranded RNA analogue that activates TLR3. In order to determine if atopy per se influences anti-viral responses, both atopic and non-atopic subjects who did not have asthma were studied.

\section{MATERIALS AND METHODS}

\section{Subjects}

This case-control study forms part of a larger longitudinal birth cohort study that has been described elsewhere [17]. 17 subjects with currently active, atopic asthma had a diagnosis of asthma confirmed by a physician and reported wheeze during the past year. Control subjects included 29 subjects with atopy but no asthma, together with 21 non-atopic, non-asthmatic subjects (healthy controls) (table 1). Atopy was defined as any one of the following: a positive skin prick test (SPT) result (weal diameter $\geqslant 3 \mathrm{~mm}$ ); specific immunoglobulin $(\mathrm{Ig}) \mathrm{E}$ $\left(\geqslant 0.35 \mathrm{kU} \cdot \mathrm{L}^{-1}\right)$ to at least one allergen; or total serum $\mathrm{IgE}$ $\geqslant 150 \mathrm{kU} \cdot \mathrm{L}^{-1}$. The following allergens were used: Dermatophagoides pteronyssinus, peanut, food mix (specific IgE only), rye grass, couch/bermuda grass, mould mix and grass mix (SPT only). Written consent was obtained from the parents and assent from the subjects. The study was approved by the Human Ethics Committee, Princess Margaret Hospital for Children (Perth, Australia).

\section{Cell preparation and culture}

Blood samples were collected into an equal volume of RPMI 1640 (Invitrogen-Life Technologies, Melbourne, Australia) containing preservative-free heparin $\left(20 \mathrm{U} \cdot \mathrm{mL}^{-1}\right)$. Peripheral blood mononuclear cells (PBMC) were isolated by density gradient centrifugation and cryopreserved in liquid nitrogen, as described previously [18]. This procedure does not distort cellular immune responses [19, 20], and has been used routinely in our laboratories in numerous studies over the last 15 yrs.

For functional studies and flow cytometry, PBMC were thawed, counted and resuspended at $1 \times 10^{6}$ viable cells $\cdot \mathrm{mL}^{-1}$ in RPMI 1640 supplemented with $10 \%$ fetal calf serum and gentamicin. TLR activation was assessed by culturing PBMC in

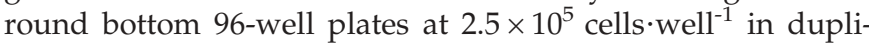
cate in medium alone (unstimulated control), with poly I:C $\left(50 \mu \mathrm{g} \cdot \mathrm{mL}^{-1}\right.$; Sigma, Castle Hill, Australia) or with imiquimod (R837) $\left(1 \mu \mathrm{g} \cdot \mathrm{mL}^{-1}\right.$, optimal dose based on our dose-response studies; data not shown) and used by BERGHOFER et al. [21] (InvivoGen, San Diego, CA, USA) at $37^{\circ} \mathrm{C}, 5 \% \mathrm{CO}_{2}$ for $6 \mathrm{~h}$. This time duration was chosen based on preliminary time-response experiments, shown in supplementary figures 1 and 2, which showed peak mRNA expression at $6 \mathrm{~h}$. In some experiments, PBMC were cultured in the presence or absence of dexamethasone (Sigma) at concentrations between $10^{-6} \mathrm{M}$ and $10^{-10} \mathrm{M}$. Cell pellets were stored in lysis buffer (Qiagen Pty Ltd, Clifton Hill, Australia) at $-20^{\circ} \mathrm{C}$ until RNA extraction.

\section{TABLE 1 Characteristics of the study groups}

\begin{tabular}{|c|c|c|c|}
\hline Subjects $\mathbf{n}$ & 21 & 29 & 17 \\
\hline Age yrs & $14.3 \pm 0.3$ & $14.1 \pm 0.1$ & $14.0 \pm 0.3$ \\
\hline \multicolumn{4}{|l|}{ Sensitisation $\mathbf{n}^{\#}$} \\
\hline Dermatophagoides pteronyssinus & 0 & 22 & 14 \\
\hline Total serum $\lg E \mathrm{kU} \cdot \mathrm{L}^{-1}$ & $17.8(9.7-30.1)$ & $121.6(45.6-310.1)^{\star \star \star}$ & $233.1(63.9-847.8)^{* \star *}$ \\
\hline
\end{tabular}




\section{Real-time PCR analysis of MxA, OAS, IRF7 and IL-10 mRNA expression}

Total RNA was extracted from the cell pellets using the RNeasy 96 Kit (Qiagen Pty Ltd) and reverse transcribed using the Omniscript II kit (Qiagen Pty Ltd) with oligo-dT primers (Promega, Madison, WI, USA) and RNase inhibitor (Perkin Elmer, Boston, MA, USA) according to the manufacturer's directions. Single-stranded cDNA was diluted 1:5 and realtime PCR performed using the QuantiTect SYBR green PCR kit (Qiagen Pty Ltd) on the ABI PRISM 7900HT (Applied Biosystems, Melbourne, Australia). Intron-spanning primers for IRF7, MxA, OAS and IL-10 were designed in-house using Primer Express Software (Applied Biosystems) or purchased directly (Applied Biosystems). Full details of primer sequence and PCR conditions can be found in the online supplementary material. Melting curve analysis was performed to assess the specificity of the assay. Copy numbers were determined by 10fold serial dilution of PCR product or plasmid standards and normalised to the reference gene UBE2D2 [22]. Data are expressed as a ratio of stimulated to control (unstimulated) samples.

\section{IL-6, IL-10 and IP-10}

The level of IL-6 and IL-10 protein was analysed from the cell culture supernatants using time-resolved fluorometry (limit of detection $10 \mathrm{pg} \cdot \mathrm{mL}^{-1}$ ) as described in detail elsewhere $[23,24]$. Antibody pairs were obtained from BD Biosciences (Sydney, Australia). Standard curves were generated using serial dilutions of recombinant IL-6 or IL-10 (BD Biosciences). For detection, europium-labelled streptavidin was added first, followed by enhancement solution (both from Delfia Wallac, Turku, Finland). The level of IP-10 was also analysed in the cell culture supernatant using standard ELISA techniques as suggested by BD Biosciences. Antibody pairs and recombinant IP-10 used to obtain a standard curve were all obtained from BD Biosciences. All protein data are expressed as delta values (protein level in stimulated samples minus protein level in control samples).

\section{Statistical analysis}

The statistical significance of differences between groups was first analysed by an ordered version of the Kruskal-Wallis test, namely the Jonckhere-Terpstra test [25]. This test assumes that the groups are inherently ordered (as shown by the increasing IgE levels across the healthy, atopic and atopic asthma groups) (table 1$)$. In the event that a significant difference $(p<0.05)$ was found, pair-wise comparisons were then analysed using the Mann-Whitney U-test. In cases where IL-6 delta values were $\leqslant 0$, an arbitrary value of 5 was assigned to allow them to be plotted on a log scale, but the statistics were performed on the raw data. Differences between groups in sensitisation patterns were analysed using Fisher's exact test and differences between paired samples were assessed using the Wilcoxon matched pairs signed-rank test. Spearman's rho was used to assess correlation. SPSS for Mac OS X (SPSS Inc., Chicago, IL, USA) was used in the analysis of the data and $p<0.05$ was considered statistically significant.

\section{RESULTS}

\section{Study population}

The characteristics of the study groups are outlined in table 1. The pattern of sensitisation was similar in atopic subjects with or without asthma, with the exception that more asthmatics had specific IgE to "food mix" than atopic non-asthmatics $(p=0.048$; data not shown). Both the atopic asthmatic and atopic non-asthmatic group had significantly higher total $\operatorname{IgE}$ levels than the healthy control group $(\mathrm{p}<0.001$ for both comparisons). $11(64.7 \%)$ asthmatics were prescribed inhaled corticosteroids (ICS) at the time of the study.

\section{Responses to TLR3 and TLR7 stimulation}

PBMC were stimulated with poly I:C (TLR3 ligand) and imiquimod (TLR7 ligand), and the results expressed as a ratio to unstimulated cells. Control, unstimulated cells showed detectable levels of IRF7, MxA and OAS expression by realtime PCR, which were markedly increased following stimulation ( $\mathrm{p}<0.001$; data not shown). There was no statistical difference between any of the groups in IRF7, MxA and OAS expression by unstimulated cells (data not shown). In initial time-course experiments (supplementary figs 1 and 2), expression of IRF7, MxA and OAS was readily induced by $6 \mathrm{~h}$, and remained stable at $24 \mathrm{~h}$. All experimental end-points were, therefore, measured at $6 \mathrm{~h}$ following stimulation.
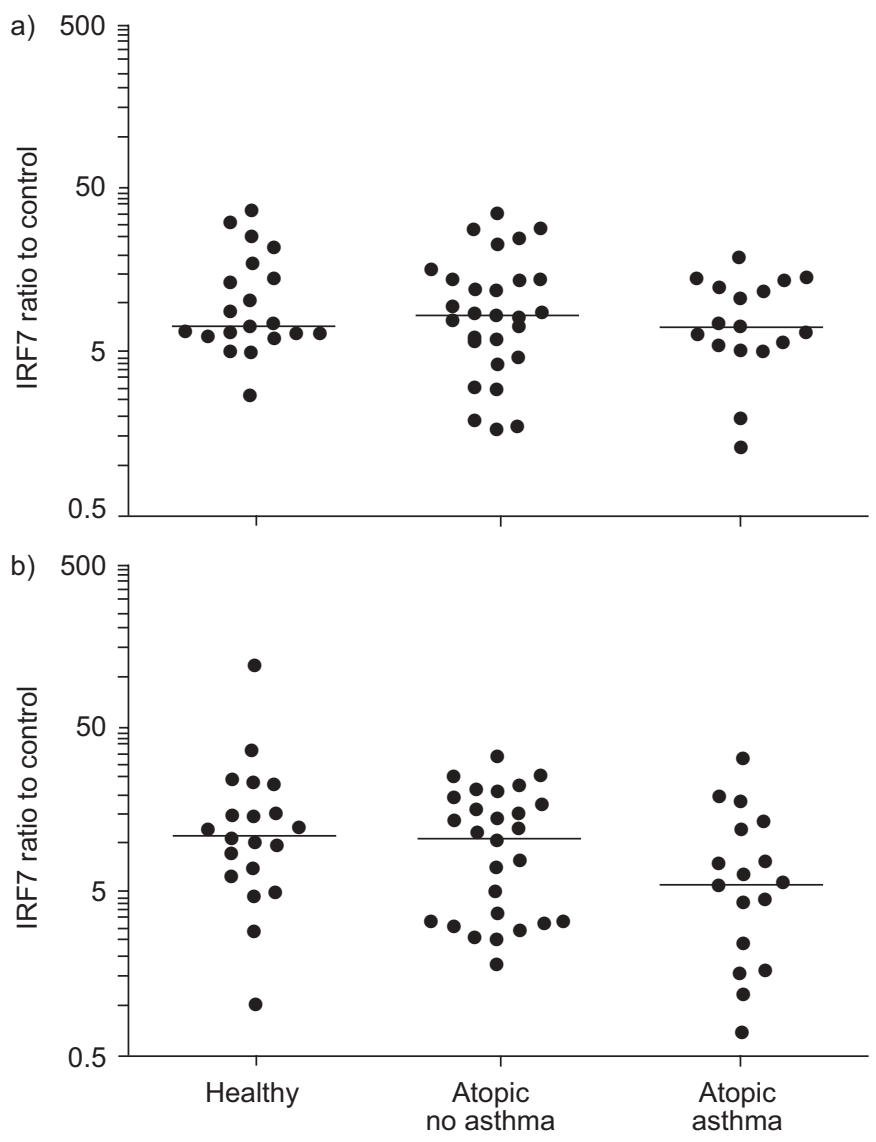

FIGURE 1. Interferon regulatory factor (IRF)7 expression following a) Toll-like receptor (TLR)3 (poly I:C) or b) TLR7 (imiquimod) stimulation, plotted on a log scale. mRNA expression is presented as the ratio of stimulated to control (unstimulated) samples. Horizontal lines indicate the median value. Statistical significance was assessed by the ordered Kruskal-Wallis test $(p=0.065)$. 


\section{IRF7 gene transcription}

Following TLR7 stimulation, there was a trend for reduced IRF7 expression in the atopic asthmatic group compared with the healthy subjects (fig. 1), but this was not statistically significant. In contrast, IRF7 expression was similar in all three groups following TLR3 stimulation.

\section{OAS and MxA gene transcription}

Following TLR7 stimulation, both OAS and MxA expression were significantly lower in asthmatic subjects than in the two healthy control groups $(p=0.003$ and $p=0.041$, respectively; figs 2 and 3). Again, there was no difference between healthy control subjects and atopic non-asthmatic subjects for either MxA or OAS. In contrast, OAS and MxA expression was similar in all three groups following TLR3 stimulation.

\section{IP-10, IL-10 and IL-6 protein expression}

Following TLR7 stimulation, protein levels of IP-10 were significantly $(p=0.001)$ reduced in the cell culture supernatants from asthmatic subjects compared with healthy control subjects (fig. 4). In contrast, following TLR3 stimulation there was no difference in IP-10 levels between the three patient groups (fig. 4). This is consistent with the mRNA data of the
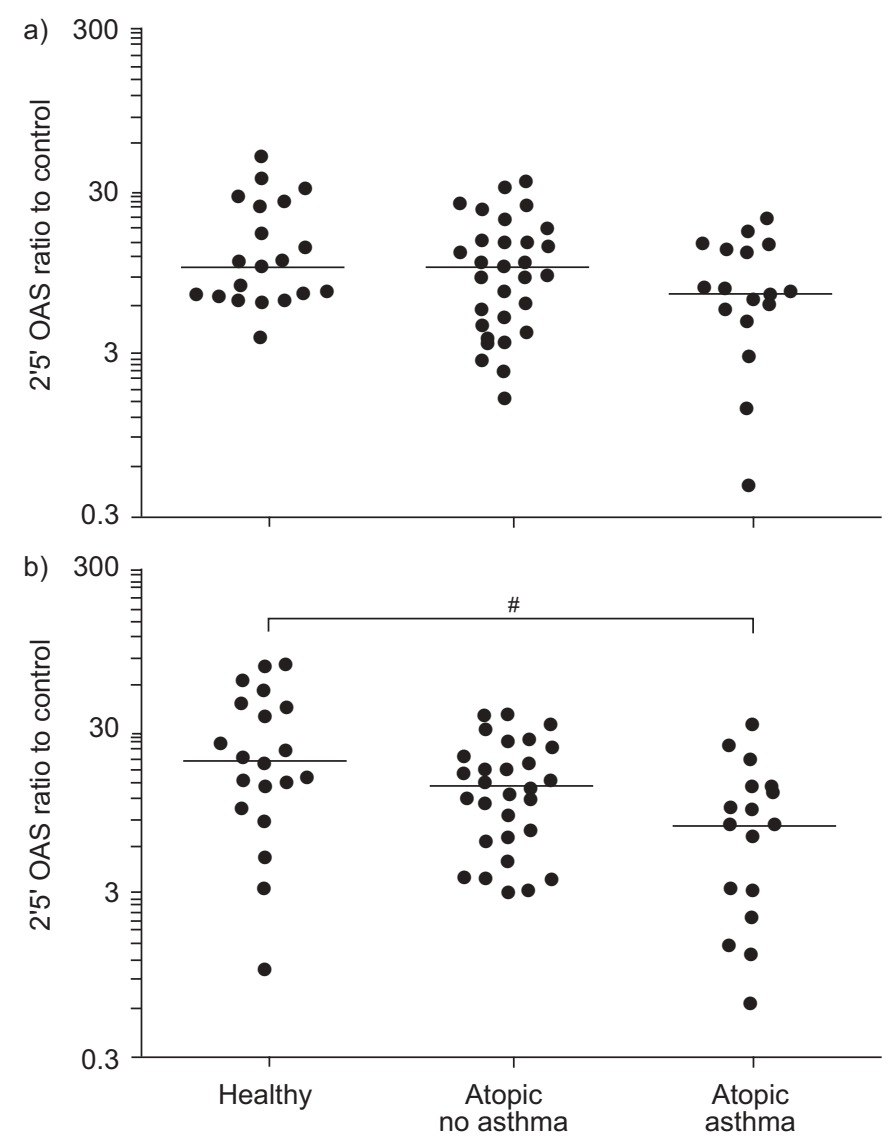

FIGURE 2. $2^{\prime} 5^{\prime}$ Oligoadenylate synthetase (OAS) expression following a) Tolllike receptor (TLR)3 (poly I:C) or b) TLR7 (imiquimod) stimulation, plotted on a log scale. mRNA expression is presented as the ratio of stimulated to control (unstimulated) samples. Horizontal lines indicate the median value. Statistical significance was first assessed by the ordered Kruskal-Wallis test $(p=0.002)$. \#: $p=0.003$ from pair-wise Mann-Whitney tests. anti-viral molecules presented previously. Furthermore, when data from all three patient groups were analysed together there was a significant negative correlation between the amount of IP-10 produced following TLR7 stimulation and total serum IgE (Spearman's rho $\mathrm{r}^{2}=-0.350, \mathrm{p}=0.008$ ).

In order to determine whether the reductions in OAS and MxA gene transcription and IP-10 production seen in asthma might reflect a general impairment of innate immune function, we also investigated the cytokines IL-6 and IL-10. IL-6 protein production was easily detectable following both TLR3 and TLR7 stimulation. However, IL-10 protein production was only detectable after TLR3 stimulation, which showed no significant difference in the concentration of IL-10 protein between the controls and asthmatics (mean \pm SE $1,491.6 \pm 220.0 \mathrm{pg} \cdot \mathrm{mL}^{-1}$ and $1,524.5 \pm 376.9 \mathrm{pg} \cdot \mathrm{mL}^{-1}$, respectively). As the concentration of IL-10 was below the level of detection $\left(10 \mathrm{pg} \cdot \mathrm{mL}^{-1}\right)$ following TLR7 activation, IL-10 mRNA expression was measured. In agreement with the protein data, IL-10 mRNA expression did not differ significantly between asthmatics and the two control groups when the cells were stimulated via TLR3 (fig. 5). Similarly, stimulation via TLR7 showed no difference in IL-10 mRNA expression between the asthmatic and control groups
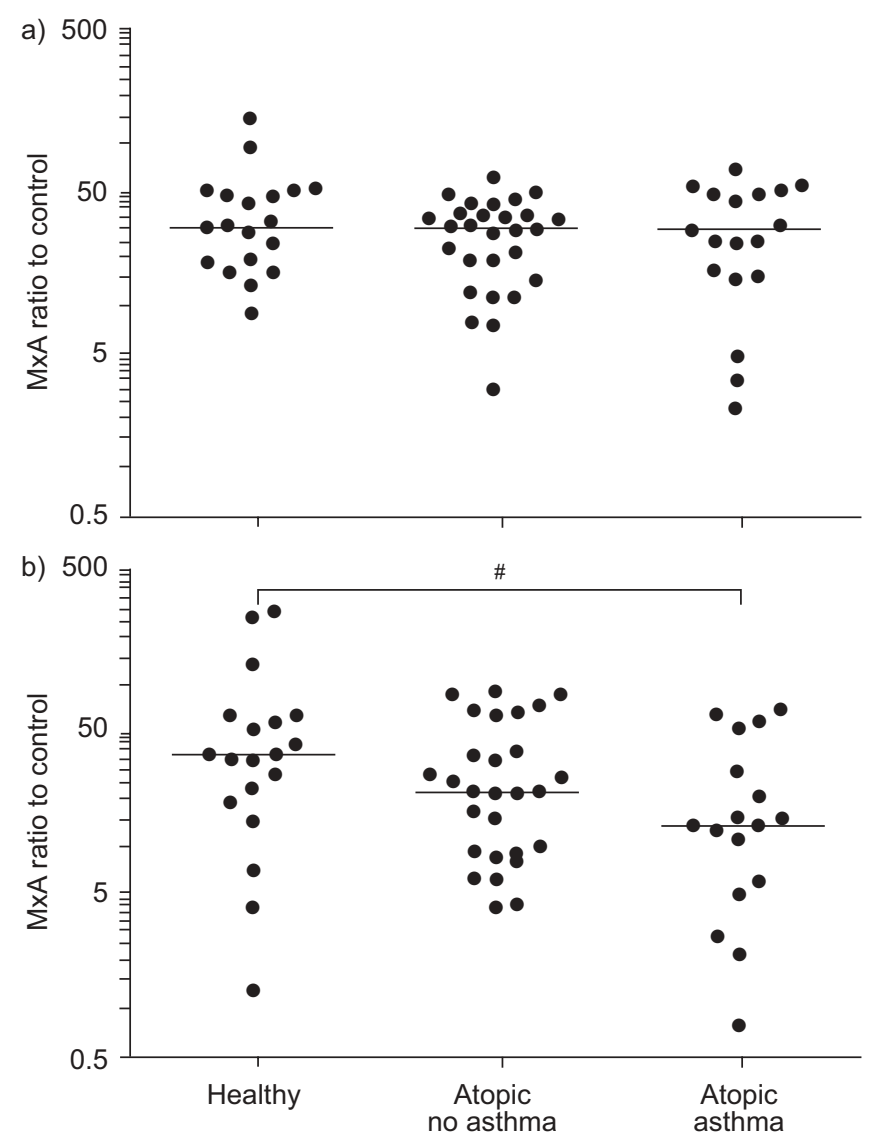

FIGURE 3. Myxovirus resistance protein A (MxA) expression following a) Tolllike receptor (TLR)3 (poly I:C) or b) TLR7 (imiquimod) stimulation, plotted on a log scale. mRNA expression is presented as the ratio of stimulated to control (unstimulated) samples. Horizontal lines indicate the median value. Statistical significance was first assessed by the ordered Kruskal-Wallis test $(p=0.024)$. \# : $p=0.041$ from pair-wise Mann-Whitney tests. 

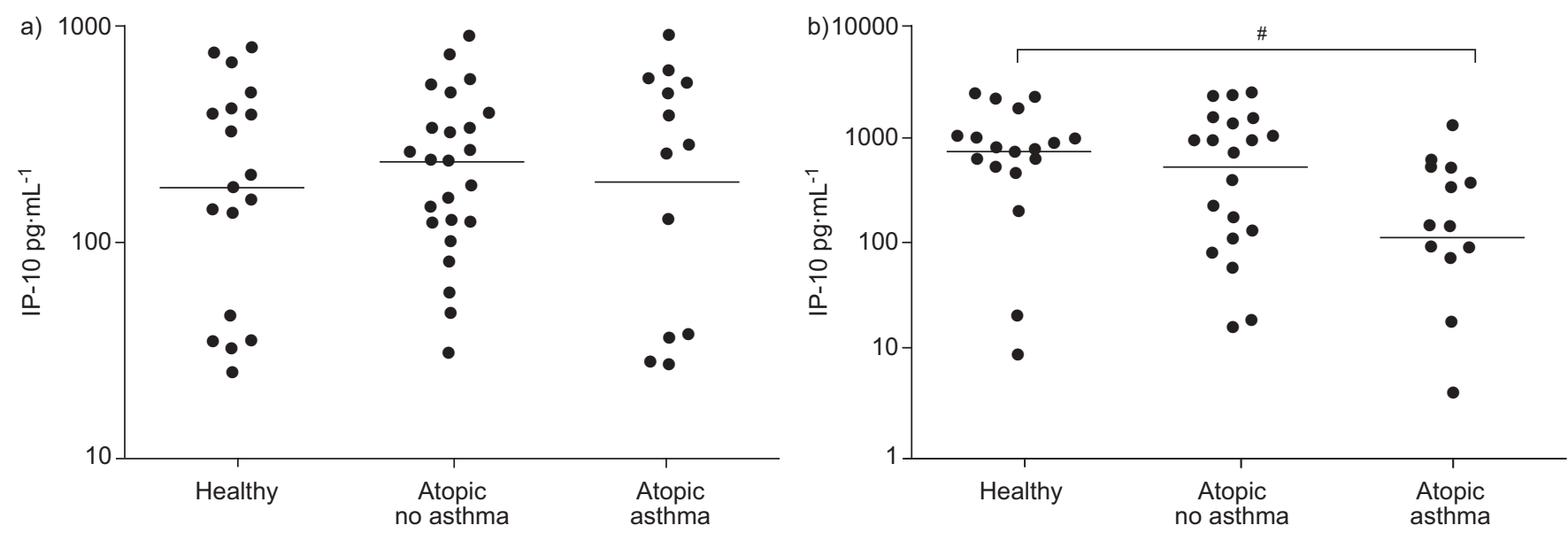

FIGURE 4. Interferon- $\gamma$-inducible cytokine protein (IP)-10 production following a) Toll-like receptor (TLR)3 (poly I:C) or b) TLR7 (imiquimod) stimulation, plotted on a log scale. Data are presented as the delta values (stimulated minus control). Horizontal lines indicate the median values. Statistical significance was first assessed by the ordered Kruskal-Wallis test $(p=0.007) .{ }^{*}: p=0.001$ from pair-wise Mann-Whitney tests.

(fig. 5). In relation to IL-6 release, stimulation via TLR3 induced a larger response than stimulation via TLR7. However, the pattern of IL-6 release did not differ significantly between asthmatics and the two control groups, regardless of whether the cells were stimulated via TLR3 or TLR7 (fig. 5).
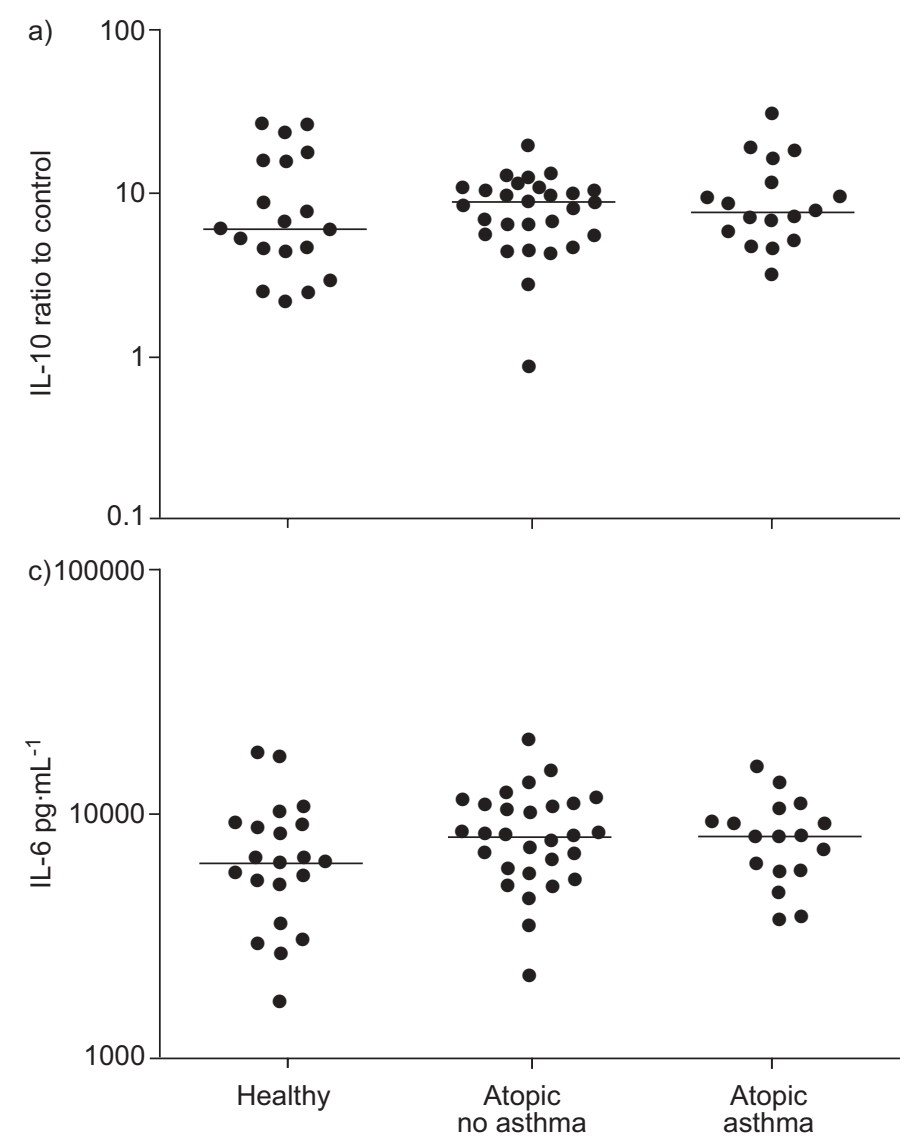

\section{Effect of corticosteroids on TLR3 and TLR7 function}

Because 11 out of the 17 asthmatic subjects in the study were prescribed ICS at the time of the study, it was important to determine whether this might influence in vitro cellular responses. However, IRF7, OAS and MxA expression after
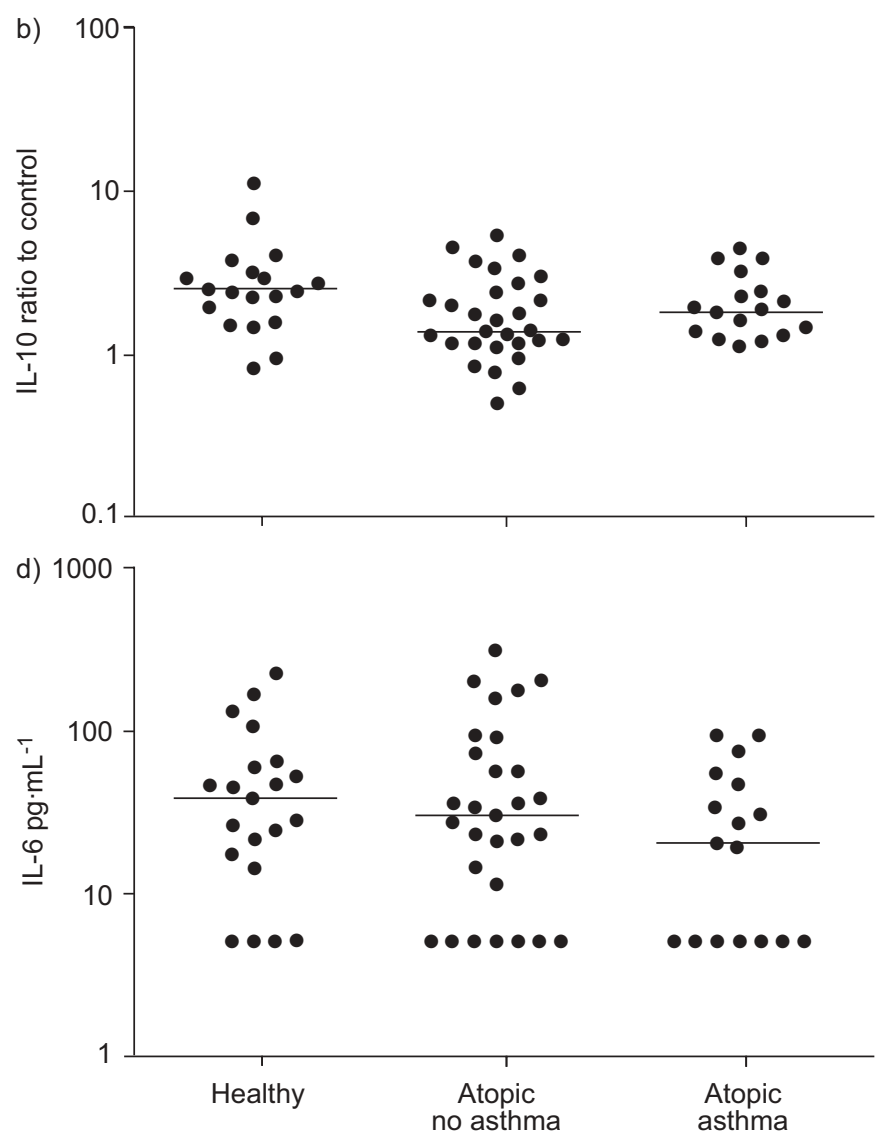

FIGURE 5. a, b) Interleukin (IL)-10 expression and c, d) IL-6 release following Toll-like receptor (TLR)3 (poly I:C; a, c) or TLR7 (imiquimod; b, d) stimulation, plotted on a log scale. IL-10 mRNA is presented as the ratio of stimulated to control (unstimulated) samples. Horizontal lines indicate the median value. IL-6 protein levels are shown as delta values (stimulated minus control). Delta values $<0$ were given an arbitrary value of 5 (half the limit of detection). 

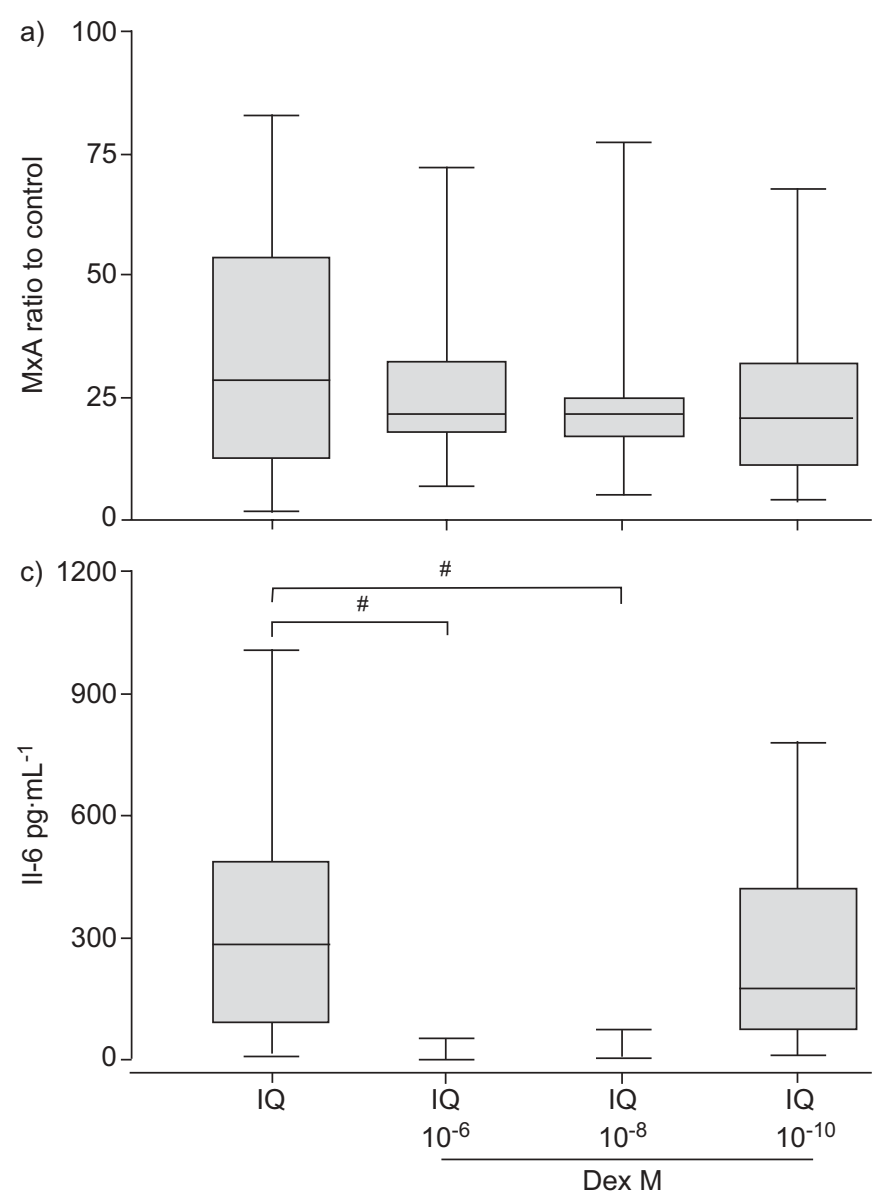

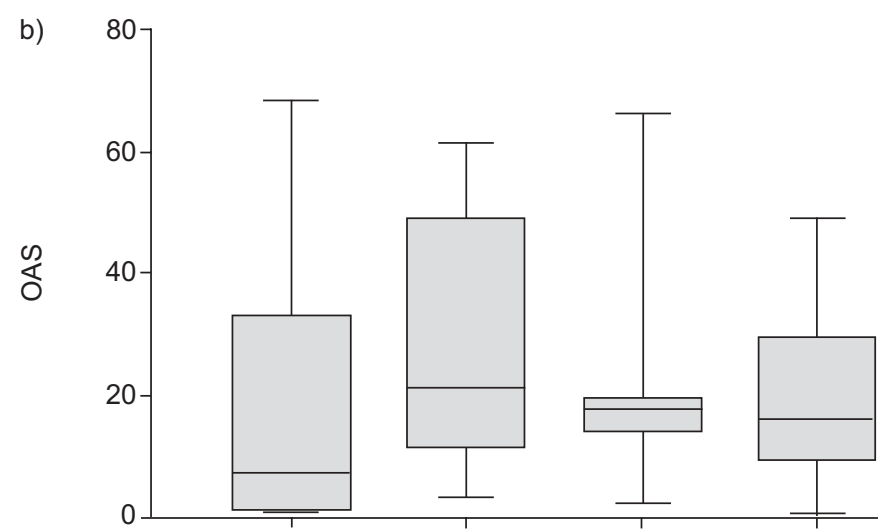

a)

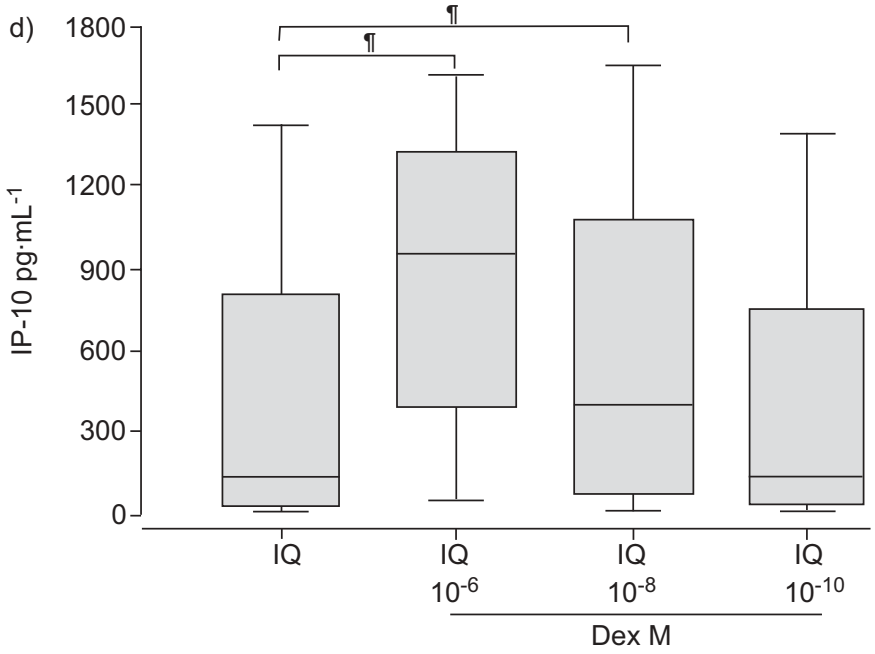

FIGURE 6. Effect of dexamethasone (dex) on Toll-like receptor (TLR)7 (imiquimod; IQ) responses. Myxovirus resistance protein A (MxA) and $2^{\prime} 5^{\prime}$ oligoadenylate synthetase (OAS) mRNA expression levels are presented as ratio of stimulated to control (unstimulated) samples. Interleukin (IL)-6 and interferon- $\gamma$-inducible cytokine protein (IP)-10 levels are shown as delta values (stimulated minus control). $n=8 .{ }^{\#}: p=0.012 ;{ }^{\circ}: p=0.017$. The $p$-values are from Wilcoxon-matched pairs signed-rank test for paired responses.

TLR3 or TLR7 stimulation were not significantly different in asthmatic subjects prescribed ICS and those who were not (data not shown). Due to limited availability of cells from the adolescent cohort, adult PBMC were stimulated in vitro with imiquimod and dexamethasone. The addition of dexamethasone at concentrations between $10^{-6} \mathrm{M}$ and $10^{-10} \mathrm{M}$ to cell cultures had no discernible effect on MxA or OAS transcription after TLR7 stimulation (fig. 6), whereas dexamethasone significantly inhibited IL-6 $(p=0.012)$ and increased IP-10 $(p=0.017)$ synthesis in a dose-dependent manner (fig. 6).

\section{DISCUSSION}

The precise mechanisms responsible for viral-induced asthma exacerbations are not well understood, but impairment of innate immunity appears to play a crucial role. The novel findings to emerge from our study were that PBMC from asthmatic adolescents showed reduced OAS and MxA mRNA expression and reduced IP-10 production following TLR7 activation via imiquimod, compared with healthy control subjects. Moreover, there was a significant negative correlation between total serum IgE and the amount of IP-10 produced following TLR7 stimulation. In contrast, TLR3 function appeared to be normal, with similar IRF7, OAS and MxA mRNA expression and IP-10 levels in asthmatic and control subjects.
Several groups of investigators have reported that cultured cells from adults and children with asthma synthesise less type I and type III IFN in response to in vitro infection with live viruses [710]. Our study adds to these earlier studies by highlighting abnormal TLR7 function in asthma, implying that an impaired response to viral ssRNA (the natural ligand for TLR7) may contribute to impaired anti-viral innate immunity in this disease. Interestingly, variants in the TLR7 gene appear to be risk factors for chronic hepatitis $C$ virus infection [26]. To our knowledge, no previous studies have examined TLR7 function in asthma, although it has recently been reported that genetic variants in the TLR7 gene, and the closely related TLR 8 gene, are associated with asthma and other atopic disorders [27].

Before considering the significance of these findings in relation to asthma, it is important to consider other potential confounding factors. Atopy in the absence of asthma was not associated with changes in TLR7 or TLR3 function. Nor did we find any evidence that variations in growth or pubertal status might explain our findings. All of the young females studied had reached menarche, and most of the young males had entered puberty as determined by Tanner stage. Height was not associated with innate immune responses (data not shown). Although many of the asthmatics had been prescribed an ICS, it appears most unlikely that our in vitro findings can 
be attributed to these medications, as IRF7, OAS and MxA expression did not vary with ICS use. Moreover, OAS and MxA expression by stimulated PBMC appeared relatively resistant to dexamethasone exposure in vitro, even at concentrations up to $10^{-6} \mathrm{M}$. These concentrations are far greater than the likely serum corticosteroid levels in asthmatics treated with low to moderate doses of ICS.

It is noteworthy that, although TLR7 function was impaired in asthma, the ability of a TLR3 ligand to induce key anti-viral molecules was similar in asthmatic and control groups. This may relate to the distinct signalling pathways induced by TLR7 and TLR3 to activate immune response genes. Whereas TLR7 utilises the adaptor protein MyD88, TLR3 signals via the adaptor protein TRIF and is relatively independent of MyD88 [28].

The molecular mechanisms leading to impaired TLR7 function in asthma are likely to be complex, and will be the focus of future investigation. TLR7 was expressed to a similar degree in unstimulated PBMC from asthmatic and control subjects (data not shown). IRF7 is an upstream regulator of IFN genes, so the trend for low IRF7 expression we observed in asthma would be predicted to produce low IFN gene transcription. However, several reports indicate that live viruses and TLR7 ligands can also directly induce downstream anti-viral pathways, independently of IFN [29-31]. This is another potential mechanism in asthma that might subsequently lead to reduced transcription of downstream anti-viral genes such as MxA and OAS, and reduced synthesis of IP-10. It is reported that RV-exposed PBMC from asthmatic subjects produce more IL-10 than PBMC from healthy controls [32]. However, we found similar expression of this immuno-regulatory cytokine in TLR3- and TLR7-activated PBMC in all groups; thus, IL-10 does not seem to explain the impaired TLR7 function seen in asthma.

We must acknowledge the limitations of the current study. Our findings were based on IRF7, OAS and MxA mRNA expression by real-time PCR, and we did not measure protein expression of these molecules. All three are intra-cellular proteins that cannot be measured in culture supernatant, and the volume of blood collected in the study did not provide sufficient cellular material to perform western blotting or to measure IRF7 phosphorylation and its translocation from the cytoplasm to the nucleus. To address this lack of protein data we measured levels of IP-10, a chemokine that has been closely linked to viral exacerbations of asthma [16], in culture supernatants following TLR stimulation. In agreement with the mRNA data, reduced protein production of IP-10 following TLR7, but not TLR3, stimulation in cultures from asthmatic adolescents strengthens the notion that TLR7 function is reduced in asthmatics compared with healthy subjects.

The study subjects with asthma had mild to moderate disease, so it will be important for future studies to examine TLR7 function in a wider range of disease severity, and in patients of varying ages. It seems unlikely that the findings we have described are specific for asthma in adolescence, especially as the reduced TLR7 function and reduced expression of antiviral molecules is in broad agreement with previous reports of low IFN synthesis by airway epithelial cells and immune cells from asthmatic children and adults [7-10].
Studies using live viruses and molecules targeted at specific viral recognition receptors are likely to provide complementary information in dissecting the mechanisms of anti-viral innate immunity. Although our findings highlight the potential importance of TLR7 function in asthma, this does not rule out abnormalities in the function of other viral detection receptors in asthma, such as retinoic acid-inducible gene I and melanoma differentiation associated protein-5. Better understanding of innate immune responses will be fundamental to developing novel therapeutic approaches to virus infections in asthma.

\section{SUPPORT STATEMENT}

The study was funded by the National Health and Medical Research Council (Canberra, Australia), the Academy of Finland (Helsinki, Finland) and the Asthma Foundation of Queensland (Fortitude Valley, Australia).

\section{STATEMENT OF INTEREST}

None declared.

\section{ACKNOWLEDGEMENTS}

The authors wish to thank the study participants and their families.

\section{REFERENCES}

1 Gern JE. Rhinovirus respiratory infections and asthma. Am J Med 2002; 112: Suppl. 6A, 19S-27S.

2 Johnston SL, Pattemore PK, Sanderson G, et al. Community study of role of viral infections in exacerbations of asthma in 9-11 year old children. BMJ 1995; 310: 1225-1229.

3 Nicholson KG, Kent J, Ireland DC. Respiratory viruses and exacerbations of asthma in adults. BMJ 1993; 307: 982-986.

4 Corne JM, Marshall C, Smith S, et al. Frequency, severity, and duration of rhinovirus infections in asthmatic and non-asthmatic individuals: a longitudinal cohort study. Lancet 2002; 359: 831-834.

5 Xatzipsalti M, Kyrana S, Tsolia M, et al. Rhinovirus viremia in children with respiratory infections. Am J Respir Crit Care Med 2005; 172: 1037-1040.

6 Kling S, Donninger H, Williams Z, et al. Persistence of rhinovirus RNA after asthma exacerbation in children. Clin Exp Allergy 2005; 35: 672-678.

7 Contoli M, Message SD, Laza-Stanca V, et al. Role of deficient type III interferon-lambda production in asthma exacerbations. Nat Med 2006; 12: 1023-1026.

8 Wark PA, Johnston SL, Bucchieri F, et al. Asthmatic bronchial epithelial cells have a deficient innate immune response to infection with rhinovirus. J Exp Med 2005; 201: 937-947.

9 Bufe A, Gehlhar K, Grage-Griebenow E, et al. Atopic phenotype in children is associated with decreased virus-induced interferon- $\alpha$ release. Int Arch Allergy Immunol 2002; 127: 82-88.

10 Gehlhar K, Bilitewski C, Reinitz-Rademacher K, et al. Impaired virus-induced interferon-alpha2 release in adult asthmatic patients. Clin Exp Allergy 2006; 36: 331-337.

11 Johnston SL. Innate immunity in the pathogenesis of virus-induced asthma exacerbations. Proc Am Thorac Soc 2007; 4: 267-270.

12 Pichlmair A, Reis e Sousa C. Innate recognition of viruses. Immunity 2007; 27: 370-383.

13 Honda $\mathrm{K}$, Yanai $\mathrm{H}$, Negishi $\mathrm{H}$, et al. IRF-7 is the master regulator of type-I interferon-dependent immune responses. Nature 2005; 434: 772-777.

14 Haller O, Kochs G. Interferon-induced mx proteins: dynamin-like GTPases with antiviral activity. Traffic 2002; 3: 710-717. 
15 Malathi K, Paranjape JM, Bulanova E, et al. A transcriptional signaling pathway in the IFN system mediated by $2^{\prime}-5$ 'oligoadenylate activation of RNase L. Proc Natl Acad Sci USA 2005; 102: 14533-14538.

16 Wark PA, Bucchieri F, Johnston SL, et al. IFN- $\gamma$-induced protein 10 is a novel biomarker of rhinovirus-induced asthma exacerbations. J Allergy Clin Immunol 2007; 120: 586-593.

17 Oddy $\mathrm{WH}$, Sherriff JL, de Klerk $\mathrm{NH}$, et al. The relation of breastfeeding and body mass index to asthma and atopy in children: a prospective cohort study to age 6 years. Am J Public Health 2004; 94: 1531-1537.

18 Macaubas C, Sly PD, Burton P, et al. Regulation of T-helper cell responses to inhalant allergen during early childhood. Clin Exp Allergy 1999; 29: 1223-1231.

19 Reimann KA, Chernoff M, Wilkening CL, et al. Preservation of lymphocyte immunophenotype and proliferative responses in cryopreserved peripheral blood mononuclear cells from human immunodeficiency virus type 1-infected donors: implications for multicenter clinical trials. The ACTG Immunology Advanced Technology Laboratories. Clin Diagn Lab Immunol 2000; 7: 352-359.

20 Upham JW, Denburg JA, O'Byrne PM. Rapid response of circulating myeloid dendritic cells to inhaled allergen in asthmatic subjects. Clin Exp Allergy 2002; 32: 818-823.

21 Berghofer B, Frommer T, Haley G, et al. TLR7 ligands induce higher IFN- $\alpha$ production in females. J Immunol 2006; 177: 2088-2096.

22 Hamalainen HK, Tubman JC, Vikman S, et al. Identification and validation of endogenous reference genes for expression profiling of $\mathrm{T}$ helper cell differentiation by quantitative real-time RT-PCR. Anal Biochem 2001; 299: 63-70.
23 Rowe J, Heaton T, Kusel M, et al. High IFN- $\gamma$ production by CD8+ T cells and early sensitization among infants at high risk of atopy. $J$ Allergy Clin Immunol 2004; 113: 710-716.

24 Taylor RC, Richmond P, Upham JW. Toll-like receptor 2 ligands inhibit TH2 responses to mite allergen. J Allergy Clin Immunol 2006; 117: 1148-1154.

25 Bewick V, Cheek L, Ball J. Statistics review 10: further nonparametric methods. Crit Care 2004; 8: 196-199.

26 Schott E, Witt H, Neumann K, et al. Association of TLR7 single nucleotide polymorphisms with chronic HCV-infection and response to interferon- $\alpha$-based therapy. J Viral Hepat 2008; 15: 71-78.

27 Moller-Larsen S, Nyegaard M, Haagerup A, et al. Association analysis identifies TLR7 and TLR8 as novel risk genes in asthma and related disorders. Thorax 2008; 63: 1064-1069.

28 Uematsu S, Akira S. Toll-like receptors and Type I interferons. J Biol Chem 2007; 282: 15319-15323.

29 Collins SE, Noyce RS, Mossman KL. Innate cellular response to virus particle entry requires IRF3 but not virus replication. J Virol 2004; 78: 1706-1717.

30 Lee J, Wu CC, Lee KJ, et al. Activation of anti-hepatitis C virus responses via Toll-like receptor 7. Proc Natl Acad Sci USA 2006; 103: 1828-1833.

31 Spurrell JC, Wiehler S, Zaheer RS, et al. Human airway epithelial cells produce IP-10 (CXCL10) in vitro and in vivo upon rhinovirus infection. Am J Physiol Lung Cell Mol Physiol 2005; 289: L85-L95.

32 Papadopoulos NG, Stanciu LA, Papi A, et al. A defective type 1 response to rhinovirus in atopic asthma. Thorax 2002; 57: 328-332. 